Perspectives: Policy and Practice in Higher Education

\title{
The interface of science: the case for a broader definition of research management
}

Marta Agostinho, Catarina Moniz Alves, Sandra Aresta, Filipa Borrego, Júlio Borlido-Santos, João Cortez, Tatiana Lima Costa, José António Lopes, Susana Moreira, José Santos, Margarida Trindade, Carolina Varela \& Sheila Vidal

To cite this article: Marta Agostinho, Catarina Moniz Alves, Sandra Aresta, Filipa Borrego, Júlio Borlido-Santos, João Cortez, Tatiana Lima Costa, José António Lopes, Susana Moreira, José Santos, Margarida Trindade, Carolina Varela \& Sheila Vidal (2020) The interface of science: the case for a broader definition of research management, Perspectives: Policy and Practice in Higher Education, 24:1, 19-27, DOI: 10.1080/13603108.2018.1543215

To link to this article: https://doi.org/10.1080/13603108.2018.1543215

Published online: 16 Nov 2018.

Submit your article to this journal $\square$

Џll Article views: 484

Q View related articles $\widetilde{ }$

View Crossmark data \lceil

Citing articles: 1 View citing articles ¿ð 


\title{
The interface of science: the case for a broader definition of research management
}

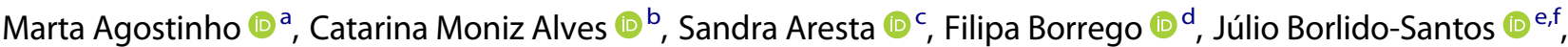

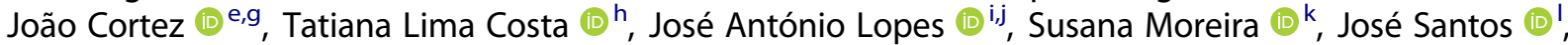 \\ Margarida Trindade (D) ${ }^{m}$, Carolina Varela (DiD ${ }^{\mathrm{n}}$ and Sheila Vidal (D) ${ }^{\circ}$ \\ ${ }^{a}$ EU-LIFE, Barcelona, Spain; ${ }^{b}$ Center for Health Technology and Services Research (CINTESIS), Faculty of Medicine, University of Porto, Porto, \\ Portugal; 'CIBIO-InBIO, Centro de Investigação em Biodiversidade e Recursos Genéticos, Laboratório Associado, Universidade do Porto, \\ Vairão, Portugal; ' INOV INESC Inovação Lisboa, Portugal; ${ }^{\mathrm{i}} \mathrm{i} 3 \mathrm{~S}$ - Instituto de Investigação e Inovação em Saúde, Universidade do Porto, \\ Porto, Portugal; f IBMC - Instituto de Biologia Molecular e Celular, Universidade do Porto, Porto, Portugal; ${ }^{9}$ INEB - Instituto Nacional de \\ Engenharia Biomédica, Universidade do Porto, Porto, Portugal; ' ${ }^{2}$ Universidade de Aveiro, Aveiro, Portugal; 'LAQV - REQUIMTE, Faculdade de \\ Ciência e Tecnologia, Universidade Nova de Lisboa, Caparica, Portugal; ${ }^{j}$ LAQV - REQUIMTE, Universidade do Porto, Porto, Portugal; ${ }^{k}$ CIIMAR/ \\ CIMAR - Centro Interdisciplinar de Investigação Marinha e Ambiental, Universidade do Porto, Matosinhos, Porto, Portugal; 'Instituto \\ Politécnico de Bragança, Bragança, Portugal; ${ }^{\mathrm{m}}$ Instituto de Tecnologia Química e Biológica António Xavier-ITQB NOVA, Universidade Nova \\ de Lisboa, Lisbon, Portugal; " School of Social Sciences and Humanities, Universidade Nova de Lisboa, Lisbon, Portugal; ${ }^{\circ}$ Instituto \\ Gulbenkian de Ciência, Oeiras, Portugal
}

\section{ABSTRACT}

This paper results from on-going reflection within the practitioners group Plataforma de Interface à Ciência (Platform of Professionals at the Interface of Science), an informal nationwide network in Portugal that brings together professionals involved in a large scope of activities related to research management, knowledge transfer and science communication. Due to the wide scope of functions and profiles of these professionals, they are not publicly nor institutionally recognised as part of the same professional group, which raises barriers for their recognition as relevant players in the research \& innovation ecosystem and full achievement of their potential. We take stock of the several definitions of their roles found in the literature and conclude on the need for an inclusive approach to consider these roles as a profession. We propose the designation of Professionals at the Interface of Science (PloS) to name this wide group of professionals that sits at the interface at all scientific disciplines.

\section{KEYWORDS}

Interface of science; research management; science communication; knowledge transfer

\section{Introduction}

The research and innovation (R\&l) ecosystem is understood as the set of infrastructure and human, financial, institutional and information resources, projects and activities organised for scientific and innovation production. It includes scientific discoveries; the creation of policy frameworks, production and management of knowledge, as well as, transfer and promotion of its application; and dissemination of science and promotion of scientific culture.

The human capital - faculty, researchers, technicians and other staff members - is a fundamental element of the ecosystem. In the last decades, the importance that activities of management, valorisation and communication of science and innovation assume in the R\&l ecosystem in general has been widely recognised, in particular by the R\&l institutions. As a consequence, there has been an increase in the demand of human resources for the management of programmes of science, technology and innovation, communication and dissemination of science, and to the monitoring of the scientific, technological and higher education systems. It is in this context that, in recent years, several claims echoed for the recognition of emergent professions at the interface of science (e.g. Langley and Ofosu 2007; Agostinho and Trindade 2014; Poli, 2018) and that in Portugal, a Platform of Professionals at the Interface of Science (Plataforma de Interface à Ciência; https://sites.google.com/view/PIC-pt) was created in November 2016.

The Platform of Professionals at the Interface of Science is an informal, nationwide network of professionals that work in the interface of all scientific disciplines in Portugal and whose main objectives are the valorisation and development of the professionals that support and add value to the national R\&l ecosystem. It gathers non-academic and semi-academic professionals holding all levels of academic degrees and working on the broader areas of the so-called research management domain, including communication and dissemination, knowledge and technology transfer, valorisation and impact, science strategy and policy support, research funding, project management, laboratory management and other areas of scientific affairs. They work in all types of research-performing 
institutions, from universities to research centres (both public and private) and research \& development (R\&D) performing companies. The term 'Professionals at Interface of Science (PloS)' was coined to define this diverse, emergent and rapidly changing community of professionals. The term 'interface of science' is related to the roles these professionals fulfil within every institution that performs scientific research. A major matter under discussion has been where the frontiers of the interface of science should be set, namely whose professionals meet the definition of working at the 'interface of science'. While performing many diverse activities, we propose these professionals share a common asset: the activities they develop are intrinsically embedded and specific to the R\&l ecosystem, albeit not including performing research per se but developing differentiated responsibilities that goes far beyond general administrative roles. As though, we highlight that the concept excludes those who are mainly dedicated to activities that are not specific to the R\&l ecosystem even if working for it, such as accounting, for example.

In this paper, we survey the literature in search of support for a wider use of the term interface of science to represent the set of functions often attributed to research managers in a broader sense.

\section{Definitions and roles of the Professionals at the Interface of Science (PIoS)}

Definitions of a potential area of action for these professionals are earmarked by their source. The Association of Commonwealth Universities (ACU) performed in 2006 a benchmarking study on international research management (Kirkland et al. 2006). It then defined research management as 'any activity instigated at the level of the institution which seeks to add value to the research activity of staff, without being part of the research process itself'. In another report published in 2008, Association of Commonwealth Universities and Global Research Management Network (2008) used the following definition: 'Research management embraces anything that universities can do to maximize the impact of their research activity'. Both definitions are remarkable because they highlight the added-value and maximisation of impact of the profession to research; however, they restrict themselves to a university context. Second, the Research and Innovation Management for Africa and the Caribbean (RIMI4AC) project, which focused on setting up and strengthening regional R\&l management networks, adds a positive effect on the environment dimension of research when claiming that the 'research manager's key roles are to make sure that their institutions' research programmes are on track, and to provide researchers with a supportive environment, smooth funding flows, assistance in identifying appropriate research partners, and administrative support' (RIMI4AC 2013).

Alternatively, other authors considered these professionals not just as supporting science but as an intrinsic part of the R\&l ecosystem. According to OECD (2015),

Research and Development (R\&D) personnel in a statistical unit include all persons engaged directly in R\&D, whether employed by the statistical unit or external contributors fully integrated into the statistical unit's R\&D activities, as well as those providing direct services for the R\&D activities (such as R\&D managers, administrators, technicians and clerical staff).

The Frascati Manual further states that:

these $R \& D$ personnel typically perform supporting functions connected to R\&D such as planning, information and financial support, legal and patent services, and assistance in assembling, adjusting, maintaining and repairing scientific equipment and instruments. Managers and administrators dealing mainly with financial and personnel matters and general administration, insofar as their activities are a direct service to $R \& D$, are included as other supporting staff. (OECD 2015)

An analysis of the published literature of the last 15 years shows that the roles of these professionals have been evolving to increasing complex and demanding functions. In the present paper, we propose that understanding the complexity of the roles under the umbrella of the interface of science will provide insights into finding an appropriate operational definition for this area. Bushaway (2003) identifies the following functions for the offices that employ research support staff: (i) contributions to the definition of research strategy and themes, and 'horizon scanning'; (ii) managing research performance metrics and benchmarking; (iii) pre-award tasks (such as research proposal development, internal peer review, costing methodologies, networking with funders); (iv) postaward management (such as contract negotiation and adherence to funder and statutory terms and conditions, project management, knowledge transfer and Intellectual Property); (v) ensuring compliance with audits from funders (e.g. European Union, research councils, research governance); (vi) portfolio management and reporting, trend analysis; and (vii) support to spinouts and commercialisation. Meyer (2010) proposed a more inclusive concept - knowledge broker - to include all the professionals that work on 'the identification and localization of knowledge, the redistribution and dissemination of knowledge, and the rescaling and transformation of this knowledge' that are creating as result of their activity a new and specific kind of knowledge. Nevertheless, the concept of 'broker' is often linked to other sectors of activity such as finance or health and this may be the reason 
why professionals at the interface of science do not identify themselves with the concept.

Thus, we propose a somewhat loose way to define the scope of functions performed by the Professionals at the Interface of Science (PloS), which accommodate different specificities and changes over time. The responsibilities at the interface of science can occur upstream (of research) - to attract/advocate for/ define strategy for research funding, projects and partnerships (with both academia and industry); at research level - to support the research activity itself (e.g. postaward management, technological platform management, ethical compliance management, intellectual property management, researchers development); and downstream (of research) - to pay back society the investment made (e.g. knowledge and technology transfer and commercialisation, outreach and science communication). Whereas the interface of science includes all areas and activities that are specific to the R\&I ecosystem in addition of research activities themselves, it excludes those activities that are universal and unspecific to all economic sectors.

\section{A brief history}

Looking back into the history of these professions can help to understand the context for some of the definitions above. Research management and administration (RMA) has been generally recognised as a profession (e.g. Langley and Ofosu 2007). Kulakowski (2006) indicates that RMA roles are expanding and continually have to adapt to the changing researchrelated political context and Lintz (2008) indicates that the role of RMAs has evolved from reactive to more proactive.

In the US, the first records on science policy and practice, considered by Beasley (2006) as the foundations of research administration, go back to the nineteenth century. According to this author, the evolution of research administration in the US relates to the development of higher education and to the evolution of research itself. By then, research administrators were scientists relying on themselves to search and secure research support and until the early 1940s the US Government policies did not include supporting scientific research (Beasley 2006). After World War II, the investment in academic research increased leading to the rapid development of research administration (Myers and Smith 2008).

To support the growth of the emerging profession and to focus on various professional and technical aspects of research administration, professional societies began to emerge, thus acting to consolidate the profession. The National Council of University Research Administrators (NCURA) was founded in 1959 in the US (NCURA 2017). The Society of Research Administrators (SRA) was founded in 1967 (SRA-I 2017) and the word 'International' was added in 1998-1999 (Myers 2007). Since then, training and professional development has been provided, namely by annual meetings and certificate programmes.

In Europe, the profession is more recent. According to Poli (2018), in the past the function of a research administrator in Europe was mainly carried out by librarians. Later on, it became a role closer to that of a financial administrator, capable to deal with budgets, accounting techniques, and aware of institutional practice and procedures (Poli 2018). In Europe, several professional associations took the initiative to create a framework for the professional development of their members (Poli and Toom 2013). As an example, the Professional Association for Research Managers and Administrators (ARMA) in the UK, was founded in 1991 (INORMS 2017) and the European Association of Research Managers and Administrators (EARMA) was created in 1995 (Heemskerk 2004). According to Poli (2018), these are the leading professional associations in Europe, both offering programmes of certifications.

In 2001, the International Network of Research Management Societies (INORMS) was established in Vancouver, British Columbia, to bring together research management societies and associations from across the globe (INORMS 2017) and has the potential to serve as the hub for international collaboration of research administrative activities (Kulakowski 2006).

A similar trend is observed regarding the Knowledge and Technology Transfer activities. Professionals of the Knowledge and Technology Transfer started to organise into associative groups as early as the 1970s: Association of University Technology Managers (AUTM) was created in mid-70s in the US, and Knowledge Commercialisation Australasia (KCA) has been promoting best practices and professionalisation of Knowledge and Technology Transfer activities in Australia and New Zealand since 1978 (KCA 2018). In Europe, the emergence of similar associations started later. ASTP-Proton, the pan-European association of professionals, resulted from the fusion in 2013 of the Association of European Science and Technology Transfer Professionals (ASTP), operating since 2000, with Proton Europe, a similar initiative that had been operating since 2003 (ASTP-Proton 2017). These associations are founding members of ATTP (Alliance of Technology Transfer Professionals), that gathers today eleven knowledge and technology transfer associations, and that promotes and maintains 'global standards in knowledge and technology transfer via the Registered Technology Transfer Professional (RTTP) designation, the international professional standard for knowledge transfer and commercialization practitioners working in universities, industry and government labs' (ATTP 2018).

In Portugal, the Technology Transfer Professionals emerged from the work in the Intellectual Properties (IP) Offices within the Portuguese Universities, and a 
network between the offices was established in 2001 (the GAPI network; Laranja 2009). The UTEN (University Technology Enterprise Network) also provides a forum for frequent meetings amongst technology transfer and commercialisation professionals (UTEN 2011).

As in the areas described above, science communication is currently an established research field and an area of action per se (Burns, O'Connor, and StockImayer 2003). Professionals working on science communication play an important role on upskilling society. In fact, it is important that citizens have the required skills to respond to the new challenges and to be prepared to apply for new jobs demands (Hanna 2016), and play their own role on the innovation processes through an inclusive economic growth, preconised by the RRI European policy (European Commission 2013). On this scenario, stakeholder engagement on innovation ecosystems are strongly dependent on science communication professionals to assure a collective knowledge accessibility.

Science communication professionals are a very diverse community of practitioners, ranging for example from journalists working in media mainstream, to communicators operating in institutional roles (institutional communicators and marketers in research organisations), and science educators based in museums or cultural organisations. There are several science communication university and master degrees offered in different parts of the world that create an increasing number of both research and practitioners in science communication.

The Public Communication of Science and Technology (PCST) Network, https://pcst.co/, is an international worldwide organisation that brings together science communicators from all continents. Similarly, EUSEA (https://www.eusea.info/) - the European Science Engagement Association - is an international community of public engagement professionals. There are several examples of science communication organisations at national level. Although the majority does not focus on professional development per se, these organisations act as networks for science communication professionals, such as for example JASC (Japan, https://www.sciencecommunication.jp/?lang=english), SCANZ (New Zealand, https://www.scanz.co.nz/), AAAS (USA, https://www.aaas.org/), AECC (Spain, http://www. wfsj.org/associations/page.php?id=109), ISCO (India, http://www.iscos.org/goals) and Sci Com (Portugal, http://scicom.pt/).

In conclusion, efforts for the establishment of professional groups emerged from different professional communities, such as from the research managers and administrators, communicators and technology transfer and valorisation communities. However, claims for the grouping of all these communities into one large, open and evolving professional group have not yet been made. We argue that grouping these professionals as an umbrella identity of interface of science allows strengthening their common role and contribution to R\&I and provides a continuum that diffuses artificial internal boundaries while acknowledging that each sub-area has its own disciplinary specificities.

\section{Common traits of the broad community of the Professionals at the Interface of Science}

Our claim for a grouping of the several roles and functions linked to the interface of science is based on common traits affecting all the professional roles described above. First, these professionals share facilitator roles, acting as brokers of knowledge in some way or another, often bringing scientific knowledge outside of the scientific community, to funders, policy makers, companies, or the public at large (Meyer 2010).

Second, this requires strong transferable competencies such as interpersonal skills, diplomacy, communication, critical thinking, organisation, but also technical knowledge about the issues being dealt with as well as a broad understanding of the scientific endeavour. Holding a scientific background, having research experience and a network of contacts in a specific area of knowledge are valuable competences which are often required to carry out functions in the interface of science more efficiently. Despite this, the interface of science roles can conceptually be carried out independently of the specific area of research.

In theory, the professionals at this interface can be easily employable by any type of research-based institution in any field of knowledge. Hence, the potential for mobility across research disciplines and institutions is a common trait of the Professionals at the Interface of Science (PloS). This common trait is mentioned in an earlier attempt to characterise this category of professionals at higher education institutions, which introduced the concept of the 'third space' as an emergent territory between academic and non-academic domains, colonised primarily by professionals where features such as loose identity, mixed backgrounds, willingness to extend beyond a given job description, and emphasis on the transferable skills are most prominent (Whitchurch 2008). Furthermore, the idea of a third space defies the conventional dichotomy prevailing in academic institutions, of an academic domain and an administrative domain that supports it (Whitchurch 2008), and define the 'double peripherality' professionals that are brokering knowledge across boundaries, as proposed by Meyer (2010).

Finally, international professional associations, such as EARMA, observe an increase in the diversity of their members' roles, and as a consequence, shape their activities to accommodate this diversity. Other associations, such as the Southern Africa Research and Innovation Management Association (SARIMA), federate from the very start professionals from different areas. 
Another important aspect, more striking in some countries than others, is the lack of a professional framework and opportunities for professional development and career progression affecting all areas of the interface of science. In countries where the interface of science community is fragile due to reduced or absent culture of professional research governance; or to reduced visibility / small numbers of professionals dispersed within many institutions; it is even more relevant to endure in a common approach to advocate for the recognition and professional development of these players.

\section{Beyond the definition: what does it imply?}

The inclusive grouping of professionals working at the interface of all scientific disciplines has several implications to the organisation of the R\&l ecosystem.

First, it builds a professional identity, and in doing so it is reasonable to expect that the professionals integrating this concept are more likely to contribute for the development of a profession and to better communicate and collaborate amongst themselves.

Secondly, the building of a professional identity and concomitant collaborative effects have potential to foster deeper - and faster - organisational change. The organisational structures where these professionals work are mainly organisations dedicated to research and education, ranging from private to public, dealing from the macro level of policy development to the operational micro-level. Taking the example of the higher education sector, the challenges related to the lack of recognition of the professional areas at the interface of science are framed by the resistance to shift power from academic staff to the new specialised roles (Poli 2018). In addition, there are thin boundaries in the functions performed by these professionals and other staff in those institutions. This physical space, manoeuvred by several agents, represents the social balance and distribution of power, as mentioned by Bourdieu (2018). In practical terms, by a clearer professional identity and its recognition, these organisations are pushed to create different career frameworks specifically adapted to these professionals and paying particular attention to entrance level, performance evaluation and salary conditions. In addition, it has the potential to raise the need to recognise a role for these professionals in the governance structures of organisations: the access to decision-making bodies within the higher education sector would be encouraged for a revision to accommodate points of entry to non-academic professionals. Moreover, in terms of education and training, the higher education institutions would need to develop education programmes for those new specialised roles. All the organisation changes fit into the quadruple helix models of research and development, where the scientific community is no longer recognised as a homogenous mass of researchers but instead a heterogenous community of different agents with distinct roles.

Thirdly, it would prompt for a formal recognition of these professions by the legislative and administrative bodies, with the support of associations and groups representing these professions.

\section{A case study: building the community in Portugal}

The Platform of Professionals at the Interface of Science was created in 2016 in response to a need felt by a community, estimated at several hundreds of professionals. Until then, there was no framework of this kind in Portugal regarding the professionals working in the areas of interface of science. The platform's mission is to contribute to the recognition and valorisation of the Professionals at the Interface of Science within the Portuguese R\&D ecosystem. Since its creation, it has focused on four areas: (1) mapping the community - a first survey carried out in May 2018 allowed to characterise and estimate at above 530 the number of active professionals in Portugal; (2) increasing the visibility of the profession; (3) identifying and disseminating training and certification opportunities, and (4) monitoring R\&l policy through advocacy and benchmarking. For example, the Platform developed position papers to include the Professionals at the Interface of Science in the Portuguese R\&D policy initiatives, e.g. the position paper on the Scientific Employment Regulation draft (REC) and the position paper on DL 57/2016 (a decree establishing a framework for contracting PhD holders). These actions have been contributing to strengthen the recognition of these professionals at the national level. The effect is evident within the members of the community itself, accelerating individual professional development and networking, but also at the level of other stakeholders of the R\&l system, such as research institutions, its governance and policy makers.

\section{Conclusions}

Research management, science communication, research policy, knowledge transfer, ethics and many other research-related activities are increasingly acknowledged as a valuable contribution for a better performance of $R \& l$ ecosystem and its institutions. However, they lack the consolidation, consistency and common identity subjacent to the contribution they bring to the R\&l ecosystem: to make it stronger and more efficient. These areas fall into the concept of research management in the broad sense. The problem with this approach is that other relevant professionals than research managers in stricto sensu do not identify themselves with it. We propose a new umbrella definition of these Professionals: Professionals at the Interface of Science (PloS), in an attempt to cover 
the broad and complex functions of this group of professionals. Similar to the third space (Whitchurch 2018) this concept defies the classic dichotomy of the research sector that divides players among 'researchers' and 'administrative' support. It also defies the simplistic and biased value perception, which is classically resistant to recognising creation of added-value by non-academics. We hereby propose that Professionals at the Interface of Science (PloS) are typically neither researchers nor administrative support personnel, but rather additional significant players that work at the interface of science, with specific professional skills and that are essential upstream, during and downstream the contemporary research endeavour by bringing specific value to the R\&l ecosystem.

As steps for further action, we propose that a more detailed characterisation of the tasks at the interface of science should be carried out, in order to ensure that other relevant roles and tasks not mentioned hereby are not excluded from the scope of the definition. International and national surveys are already being prepared to contribute to this exercise (e.g. RAAAP worldwide; https://raaapworldwide.wordpress.com/; (Kerridge and Scott 2017); Andersen et al. 2017, http://www.bestprac. eu/home/), including a specific survey to characterise the Portuguese community of professionals at the Interface of Science launched by the Platform (Martins et al. 2018). To increase recognition for the Professionals at the Interface of Science (PloS), a specific code of ethics and standards of professional conduct is also needed. In addition, we propose that on-going efforts to establish professional frameworks (BESTPRAC Report 2014-2017, http://www.bestprac.eu/home/), as well as the existing certification schemes (ARMA and EARMA Certification, https://www.earma.org/ and https://arma.ac.uk/; worldwide RTTP certification provided by ATTP and its members associations, http://attp.info/new-approach-to$\mathrm{rttp} /$ ) should reflect this broader vision of the profession. We therefore defend an approach that will allow the Professionals at the Interface of Science (PloS) to be duly recognised by relevant stakeholders, such as funding agencies, policy makers, research performing organisations and the higher education sector, and acknowledged by the added value they create for the benefit of science, innovation and the society.

\section{Disclosure statement}

No potential conflict of interest was reported by the authors.

\section{Funding}

This work was supported by European Commission: [EnvMetaGen (grant agreement no 668981)]; Fundação para a Ciência e a Tecnologia: [Grant Number LISBOA-01-0145FEDER-007654,LISBOA-01-0145-FEDER-007660,POCI-01-0145FEDER-007274,POCI-01-0145-FEDER-007746,UID/Multi/04423/ 2013,UID/QUI/50006/2013, UID/IC/4255/2013]; COMPETE2020
- Programa Operacional Competitividade e Internacionalização (POCI): [Grant Number LISBOA-01-0145-FEDER-007654, LISBOA-01-0145-FEDER-007660,POCI-01-0145-FEDER-007274, POCI-01-0145-FEDER-007746,UID/Multi/04423/2013].

\section{Notes on contributors}

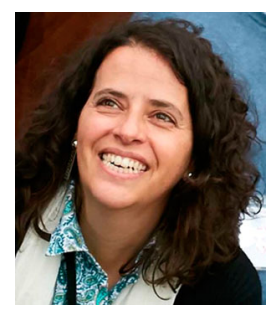

Marta Agostinho is the Coordinator of EU-LIFE, an alliance of European research institutes that aims at promoting excellence in research and acting as a voice for research institutes in the European policy landscape. Her fields of action include science policy, strategic science management and communication, outreach and public dialogue with science. She is also expert evaluator in H2020. As Coordinator of EU-LIFE, M. Agostinho overseas the implementation of the strategy of the alliance and leads the science policy area. M. Agostinho has over 10 years of experience in knowledge mediation in international settings, after a 10 years of experience of research in life sciences. In 2007 she became manager of the $\mathrm{PhD}$ programme at Instituto de Medicina Molecular (IMM), Lisbon, Portugal. From 2008-2012, she was Director of the Communication \& Training Unit at IMM, which provided a coordinated framework for Science Communication, Advanced Training and Science Funding. In 2012-2014, she became Project Manager at NOVA Medical School (FCM/UNL), responsible for the coordination of a European Joint Action in Mental Health policy with over 50 partner institutions from 27 European Countries. She was also coordinator of two advanced doctorate training disciplines on Science Communication and Research skills at the Nova Medical School.

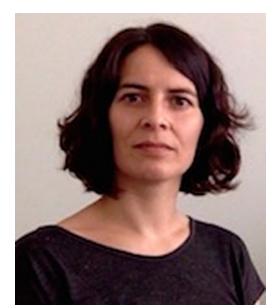

Catarina Moniz Alves holds a PhD in Biomedical Engineering (University of Minho, UM) and a Postgraduation in Project Management by the Porto Business School. She developed her post-doctoral studies at the School of Engineering and Applied Sciences at the University of Harvard (MA, USA). During her career in research she was involved in the management of different European projects, having supervised and monitored laboratory activities, as well as organising conferences, reporting, presenting results and interacting with the official bodies of the European Community. Since 2016, she is a research manager at CINTESIS - Center for Health Technology and Services Research, especially focused on project management and international funding sources. Catarina Moniz Alves has been appointed independent expert for COST, Portuguese National Innovation Agency (ANI) and Eurostars. She is author/co-author of 16 peer-reviewed publications, 7 book chapters and in more than 25 international oral communications.

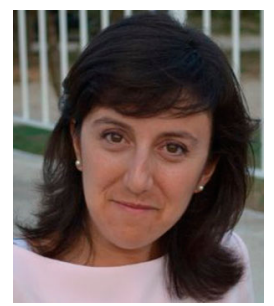

Sandra Aresta has a degree in Microbiology and Genetics from the University of Lisbon obtained in 1997 and a $\mathrm{PhD}$ in Molecular and Cellular Biology from Paris XI University obtained in 2001. After a career in research both in academia (Institut Curie, Imperial College, CRCM-Marseille) and industry (Hybrigenics), in 2007 she made a career move into technology transfer by taking a position at Institut de Recherche pour le Développement, where she was in charge of all aspects 
concerning IP protection and management, and the negotiation of licensing deals. Since February 2017 she's responsible for promoting and facilitating connections with business corporations and the public administration, and raising awareness for Intellectual Property and Knowledge Transfer at CIBIO - Research Centre in Biodiversity and Genetic Resources - InBIO Associate Laboratory.

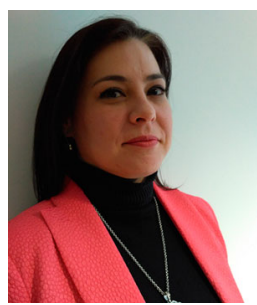

Filipa Soares Borrego is the Innovation Management Coordinator at INOV INESC Inovação, facilitating the participation of INOV, INESC ID and INESC MN researchers in European projects. Filipa was a Fulbright Visiting Scholar in the IC2 Institute of the University of Texas, Austin, USA, where she worked on methodologies to develop, license and/or commercialise earlystage technologies coming out of European projects. Filipa graduated in 1999 and received her MSc degree in 2002, both in Electronics and Telecommunications Engineering at the University of Aveiro, Portugal. In 2002, she was a trainee at the European Space Agency (ESA) in the Netherlands until 2004, when she started her PhD in Computer Architecture at Delft University of Technology, the Netherlands. In 2008 after her PhD defence, she took a position as a researcher at the Ultra Low Power DSP group at Holst Centre / IMEC, Netherlands, where she stayed until 2010. In 2010, she returned to Portugal where she started her career as Research Manager at FCT/UNL. Between March 2013 and October 2014, she was nominated National Expert for the Committee of Information and Communication Technologies (ICT) theme of the European Framework Programme Horizon 2020 as well as National Contact Point for the ICT, Future and Emerging Technologies (FET) and Electronic Components and Systems for European Leadership (ECSEL) Joint Undertaking.

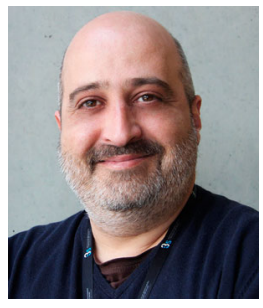

Júlio Borlido Santos is a biologist and science communicator. Over the years, he has taken part in many scientific culture initiatives and dissemination projects targeted to assorted audiences. Between 2003 and 2014 he was head of IBMC.INEB Office for Science Communication to then, in 2015, take on the coordination of i3S Communication Unit. His extensive activity encompasses participation in projects of scientific culture dissemination, as well as action-research science communication projects funded both nationally and internationally. He organises, promotes and teaches several advanced training on 'Science, Ethics and Society' for scientists and other audiences, including continuous training activities for high school teachers. He was member of Board of Director of the Scicom.pt network and is still member of many other advisory boards. Recently he has supported institutional activities on Research Integrity.

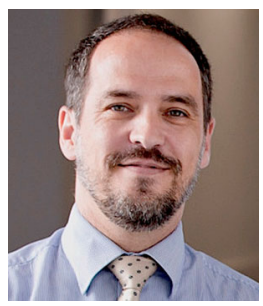

João Cortez has a PhD in Textile Chemistry (De Montfort Univ., UK) and developed a research career focusing in nanotechnology applications and technical textiles. He worked at Renova SA and Precision Processes Textiles (UK) and established several collaborations with industry (national and international), developing products/processes. He participated in national and EU projects (FP6, FP7, H2020) and is now a partner in a H2020-ICT30 project MIRACLE. In $2012 \mathrm{JC}$ became Head of INEB's Technology Transfer Office, and in 2017 became the coordinator of the Research Funding
Office at i3S. He coordinated the RESOLVE Program (a health focus acceleration programme. His expertise include project management, IPR management and technology transfer in the biomaterials and MedDev areas.

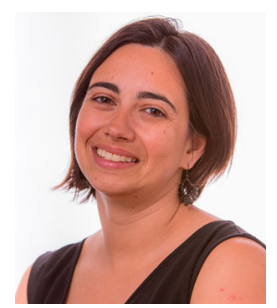

Tatiana Lima Costa holds a PhD in Biochemistry (University of Aveiro, UA) and a Postgraduation in Industrial Property Law by University of Lisbon. Currently she is Science and Technology Manager/Funding Advisor at the Research Support Office of UA, mainly supporting pre-award and internationalisation activities, including analysis and dissemination of funding opportunities, partner search and matching, development and submission of grant proposals, contract negotiation and liaison with different stakeholders (public authorities, funding agencies, academia and research centres, industry). She has been appointed independent expert for EC and EARMA assessor. Previously she integrated UA technology transfer office (2011-2014), where she dealt with intellectual property issues (patent writing, patentability assessment, registration, IPR maintenance, etc), technology assessment and evaluation, technology scouting, licensing and University-enterprise cooperation, namely in issues related to contract research and national collaborative research. During the last years she has been invited for lecturing on different courses, about funding opportunities, proposal writing and IPR/TT issues. She has also interest in research in the field of Research Management, Technology Transfer, Entrepreneurship, Technology and Innovation Management, Science and Innovation Politics, University - Enterprise Relations. She is author/co-author of 6 publications and author/co-author in more than 20 poster presentations.

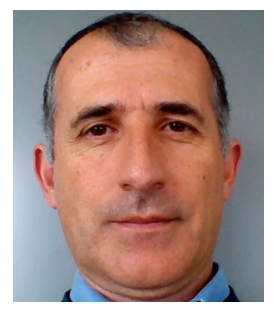

José António Lopes is a Scientific Officer at the R\&D unit REQUIMTE-LAQV (Associated Laboratory for Green Chemistry) since 2016 where he's responsible for supporting the Unit's board in all management activities and also as the main responsible for tasks related with scientometrics, impact measurement of the unit's science output and of the unit's technology and innovation strategy implementation. He has a PhD in Chemical Engineering where he developed research and technology in the Supercritical Fluids Engineering area (Separation Processes). He's the co-inventor of four patents and the author of six peerreview articles. More recently, he has worked as the education and science manager of the Bio-Engineering Systems Focus Area within the international partnership MIT Portugal Program. In parallel, he has worked for short periods of time in the university's TTO supporting knowledge and technology transfer, in developing novel technologies for private companies at IBET and also performing research in Higher Education (curriculum development and teaching methodologies in Doctoral Programs) coupled with teaching on the areas of Technology Transfer and Bioprocess Engineering.

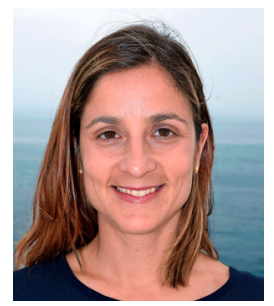

Susana Moreira - PhD in Biomedical Sciences at the University of Porto in 2005. She coordinates the Science and Innovation Office at CIIMAR, where she implements a pre-award grant managing service, including prospective analysis of funding opportunities, development and submission of grant proposals and contract negotiation. She has more than fifteen years of experience linked to marine related research and 
innovation management under regional, national and European funding schemes. She has significant working experience in the development and implementation of activities related with monitoring, dissemination and exploitation of R\&D results and public policy support. She also works as liaison officer with different actors (e.g. public authorities, funding agencies, academia and research centres, industry, including SMEs, maritime clusters) and represents CIIMAR in several national and European networks and forums. She is an Invited assistant professor at Institute of Biomedical Sciences Abel Salazar, University of Porto, being responsible for the course on Integrated Ocean Management of the Marine Sciences - Marine Resources MSc Degree She has 20 publications in international peer-reviewed journals.

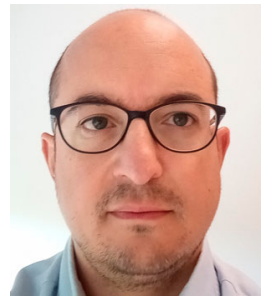

José Santos holds a PhD degree in Chemical Engineering (Univ. Leeds, UK) and is a certified Professional Project Manager. Embracing science interface positions for the last 13 years, he has spent the last 6 year providing the Research Support Office at IPB and served previously as Senior Researcher at CeNTI (PT) and Univ. Pierre et Marie Curie (FR) and Researcher at Univ. Leeds (UK), as European Projects Manager at FCT (PT) and as Lecturer at IPB (PT). He also acts as expert evaluator for several European and National Funding Agencies.

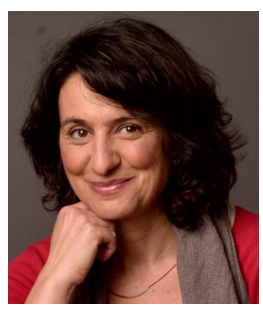

Margarida Trindade dedicates her career to Research Management, first she was Pre-award Funding Coordinator at Instituto de Medicina Molecular and then at the ISCTE-Instituto Universitário de Lisboa and, since 2016, she is the Head of the ITQB NOVA Science Funding Office in Oeiras, Portugal. She also developed training on grant application and career development for Masters' and $\mathrm{PhD}$ programmes, acted as an expert evaluator and advisor for the European Commission and other agencies and as assessor for the EARMA Certification on Research Management. Margarida Trindade holds a PhD in Development Biology from University College London, UK (2000).

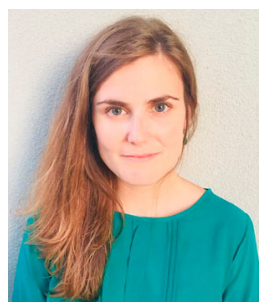

Carolina Varela has an MSc in international cooperation for development at ISEG-Lisbon School of Economics and Management of the University of Lisbon. Her career started with international cooperation projects in Spain follow by a five year experience as a research manager, most recently as a pre-award advisor at the NOVA School of Social Sciences and Humanities, Universidade Nova de Lisboa. She is an active member of several Portuguese research managers and science communicators' networks such as, the national network Plataforma de Interface à Ciência (Coordinator of Workgroup 4) and the Lisbon network Finca Pé. Her research interests focuses on the comparative analysis and international benchmarking of RDI policies.

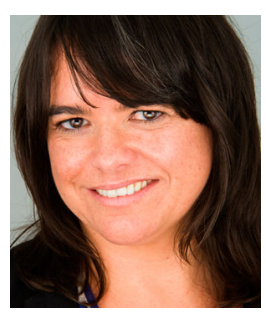

Sheila Vidal heads the Research Funding Affairs Unit at the Instituto Gulbenkian de Ciência in Oeiras, Portugal and is a founding member of the Portuguese network Plataforma de Interface à Ciência. She has fourteen years of experience in the design \& implementation of pre-award grant management strategies to successfully secure competitive funding in the Life Science domain at the individual and institution level. She has a global experience in research funding policies and regularly coordinates/ lectures advanced training modules on grant development for researchers and at several Masters and PhD programmes in Lisbon, Brazil and Cape Verde-Africa. She also acted on various occasions as an advisor for the FCT-Portugal and Portuguese Secretary of State of the Ministry of Science and Higher on grant management programmes. She is a member of the EU-LIFE Grants and Funding Working Group, the European Association of Research Manager and Administrators (EARMA) and the BESTPRAC Cost Action. Sheila Vidal holds a PhD in Innate Immunity from the University Paris XI, France.

\section{ORCID}

Marta Agostinho (D) http://orcid.org/0000-0002-0414-7689 Catarina Moniz Alves (D) http://orcid.org/0000-0001-60039159

Sandra Aresta (D) http://orcid.org/0000-0002-2384-4690 Filipa Borrego (D) http://orcid.org/0000-0002-2411-2264 Júlio Borlido-Santos (i) http://orcid.org/0000-0003-4923-9701 João Cortez (D) http://orcid.org/0000-0002-8227-0754

Tatiana Lima Costa (1) http://orcid.org/0000-0002-0675-8096 José António Lopes (D) http://orcid.org/0000-0002-6844-0593 José Santos (D) http://orcid.org/0000-0003-2103-4085

Susana Moreira (D) http://orcid.org/0000-0003-1204-8282

Margarida Trindade (D) http://orcid.org/0000-0001-6365-2602 Carolina Varela (1) http://orcid.org/0000-0002-4804-2950

Sheila Vidal (D) http://orcid.org/0000-0001-9940-1952

\section{References}

Association of Commonwealth Universities and Global Research Management Network. 2008. Research Management Staff Survey 2008. London: ACU/GRMN.

Agostinho, M., and M. Trindade. 2014. "Research Management in Portugal: A Quest for Professional Identity." Research Management Review 20 (1): 1-8.

Andersen, Jan, Martina Pöll, Ellen Schenk, Diana Pustuła, Vanessa Ravagni, Miriam Ryan, and Anne Katrin Werenskiold. 2017. BESTPRAC Report 2014-2017. The Voice of Research Administrators Building a Network of Administrative Excellence. Edited by Rebekka Steinmann. https://bestprac.eu/fileadmin/mediapool-bestprac/ documents/WS-Brussels/BESTPRAC_Booklet.pdf.

ASTP-Proton. 2017. "ASTP Organization." ASTP-Proton (Editor). http://www.astp-proton.eu/organisation/.

ATTP. 2018. "ATTP About ATTP." In ATTP (Editor). http://attp. info/learn-about-attp/.

Beasley, K. L. 2006. "The History of Research Administration." In Research Administration and Management, edited by E. C. Kulakowski, and L. U. Chronister, 9-29. Sudbury, MA: Jones and Bartlett.

Bourdieu, P. 2018. "Social Space and the Genesis of Appropriated Physical Space." International Journal of Urban and Regional Research 42: 106-114. doi:10.1111/ 1468-2427.12534.

Burns, T. W., D. J. O'Connor, and S. M. Stocklmayer. 2003. "Science Communication: a Contemporary Definition." Public Understanding of Science 12: 183-202. doi:10.1177/ 09636625030122004.

Bushaway, Robert W. 2003. Managing Research (Managing Universities and Colleges: Guides to Good Practices), edited 
by D. Warner and D. Palfreyman. Philadelphia, PA: Open University Press.

European Commission. 2013. RRI - "Options for Strengthening Responsible Research and Innovation." Directorate-General for Research and Innovation. Brussels, Belgium. Report available at https:/ec.europa. eu/research/science-society/document_library/pdf_06/ options-for-strengthening_en.pdf.

Hanna, K. 2016. Spaces to Think: Innovation Districts and the Changing Geography of London's Knowledge Economy. Global capital, Skills \& opportunity. Report available at https://www.centreforlondon.org/publication/innovationdistricts/.

Heemskerk, Frank. 2004. "Usage and Benefits of CRIS for Two Extremes: The Political Decision-Maker and the Research Manager." In Putting the Sparkle in the Knowledge Society, edited by A. Nase, and G. V. Grootel, 13-26. Leuven: Leuven University Press.

INORMS. 2017. "INORM Members." In INORMS (Editor). http:// www.inorms.net/members.html.

Kerridge, Simon, and Stephanie F. Scott. 2017. "Research Administration as a Profession (RAAAP) - A Snapshot of Research Administrators and Their Skills from Around the World." In: NCURA 59th Annual Meeting, 5-9th August 2017, Washington, DC. (Unpublished). doi:10.6084/m9. figshare.5278195.v1 .

Knowledge Commercialization Australasia. 2018. "KCA About Us." In KCA (Editor). https://www.kca.asn.au/about-us/ about-us.

Kirkland, J., S. Bjarnason, J. Stackhouse, and R. Day. 2006. International Research Management: Benchmarking Programme. London: Association of Commonwealth Universities. https://www.acu.ac.uk/focus-areas/researchmanagement-uptake/research-management-benchmarki ng/international-research-management-benchmarkingprogramme.

Kulakowski, Elliott C. 2006. "The Future of Research Administration in the 21st Century: Looking Into the Crystal Ball." In Research Administration and Management, edited by E. C. Kulakowski, and L. U. Chronister, 31-40. Sudbury, MA: Jones and Bartlett.

Langley, D., and M. Ofosu. 2007. "Celebrating a Profession: The Global Perspective." Journal of Research Administration 38 (1): 39-44.

Laranja, M. 2009. "The Development of Technology Infrastructure in Portugal and the Need to Pull Innovation Using Proactive Intermediation Policies." Technovation 29 (1): 23-34. doi:10.1016/j.technovation. 2008.07.010.
Lintz, E. M. 2008. "A Conceptual Framework for the Future of Successful Research Administration." The Journal of Research Administration 39 (2): 68-80.

Martins, M., C. Oliveira, H. Mendes, J. A. Silva, T. Costa, and C. Oliveira. 2018. "Mapping of the Portuguese Network of Research Support Professionals." PK-6 PECHA KUCHA Session 6 (14.15h), 18th April 2018. In 24th ANNUAL EARMA CONFERENCE, April 16-18, 2018, Brussels, Belgium.

Meyer, M. 2010. "The Rise of the Knowledge Broker." Science Communication 32 (1): 118-127.

Myers, P. E. 2007. "Celebrating the First Forty Years of the Society of Research Administrators International." Journal of Research Administration 38 (1): 19-30.

Myers, P. E., and M. F. Smith. 2008. “Research Administration in History: The Development of OMB Circular A-110 Through Joseph Warner's COGR Subcommittee, 1976-1979." The Journal of Research Administration 39 (2): 15-32.

NCURA. 2017. "NCURA - Membership \& Volunteering". In NCURA (Editor). NCURA, Washington, DC, USA. http:// www.ncura.edu/MembershipVolunteering.aspx.

Organisation for Economic Co-Operation and Development. 2015. Frascati Manual 2015: Guidelines for Collecting and Reporting Data on Research and Experimental Development, The Measurement of Scientific, Technological and Innovation Activities. Paris: OECD.

Poli, S. 2018. "Who Are Today's Research Managers? Roles, Professional Development, and Evolution of the Profession." In Research Management: Europe and Beyond, edited by J. Andersen, K. Toom, and S. Poli, 2-29. San Diego, CA: Academic Press.

Poli, S., and K. Toom. 2013. "Exploring the Theory. Research Management as a Newer Field of Investigation." EARMA LINK Magazine, European Association of Research Managers and Administrators, January 7-8.

Research and Innovation Management for Africa and the Caribbean. 2013. Being a Research Manager: Understanding Your Role and Maximising Your Impact. Notes for Researchers and Research Managers. Cape Town: Research Africa.

SRA-I. 2017. Society of Research Administrators International Bylaws. In edited by SRA, Arlington, VA, USA. https:// srainternational.org/about-sra-international/society-researchadministrators-international-bylaws.

UTEN. 2011. UTEN Portugal Report 2011. Report available at http://utenportugal.org/wp-content/uploads/uten-annualreport-2011.pdf.

Whitchurch, C. 2008. "Shifting Identities and Blurring Boundaries: The Emergence of Third Space Professionals in the UK Higher Education." Higher Education Quarterly 62 (4): 377-396. doi:10.1111/j.1468-2273.2008.00387.x. 